\title{
Is there a need for a formulary of clinically interchangeable medicines to guide generic substitution in Saudi Arabia?
}

\author{
Alian A. Alrasheedy ${ }^{\mathrm{a}, *}$, Mohamed Azmi Hassali ${ }^{\mathrm{a}}$, Hisham Aljadhey ${ }^{\mathrm{b}}$, \\ Mohamed Izham Mohamed Ibrahim ${ }^{c}$, Saleh Karamah Al-Tamimi ${ }^{\text {a }}$ \\ a Discipline of Social and Administrative Pharmacy, School of Pharmaceutical Sciences, Universiti Sains Malaysia, 11800 Penang, Malaysia \\ ${ }^{\mathrm{b}}$ Medication Safety Research Chair, College of Pharmacy, King Saud University, 11451 Riyadh, Saudi Arabia \\ ${ }^{\mathrm{c}}$ Research and Graduate Studies Affairs, College of Pharmacy, Qatar University, Doha, Qatar
}

\section{A R T I C L E I N F O}

\section{Article history:}

Received 26 May 2013

Accepted 15 June 2013

Available online 8 July 2013

\section{Keywords:}

Generic substitution

Generic medicines

Formulary

\begin{abstract}
A B S T R A C T
The escalating healthcare expenditure is a major challenge to sustainability of the healthcare systems. To confront the escalating health expenditure in general and medicines expenditure in particular, many countries promoted the use of generic medicines. To promote generic medicines, many countries have adopted a generic substitution (GS) policy and generic prescribing. To effectively implement the GS policy, it is evident in the literature that it is essential to have an evidence-based guide on therapeutic equivalence and formulary of interchangeable medicines to guide responsible GS. In Saudi Arabia, GS is permissive and pharmacists are given the right to perform GS. While the prescriber's approval is not a requirement, patient consent is required when performing GS. Although there are some general drug references, such as the Saudi National Formulary (SNF) and list of registered medicines in the Saudi market, but there is currently no information available to healthcare professionals that documents the therapeutic and bioequivalence between medicines. Thus, it is essential to have a formulary of interchangeable medicines to guide appropriate GS or at least to include such vital information regarding therapeutic equivalence and brand interchangeability as part of the SNF. That, in turn, will not only make healthcare professionals more confident when providing GS, but will also enable the avoidance of situations where GS is inappropriate.
\end{abstract}

Copyright @ 2013, InPharm Association, Published by Reed Elsevier India Pvt. Ltd. All rights reserved.

\section{The role of generic medicines in sustainability of healthcare systems}

To confront the escalating health expenditure in general and medicine expenditure in particular, the use of generic medicines is promoted and encouraged in many countries. ${ }^{1,2}$ Indeed, generic medicine utilization has led to substantial cost savings for the healthcare system. ${ }^{3-7}$ While generic medicines lead to substantial cost savings to the healthcare system, they provide the same health outcomes. $^{8}$ In fact, generic medicines, as equivalent versions of original brand medicines, are considered cost effective first line and standard therapy for many diseases and conditions such as hypertension, diabetes, asthma, allergies, depression, gastrointestinal disorders, infections, skin diseases, HIV/AIDS and many other diseases and conditions. ${ }^{6,9}$ Thus, by using generic medicines, the healthcare system can save a huge amount of money that can be

\footnotetext{
* Corresponding author.

E-mail address: alian-a@hotmail.com (A.A. Alrasheedy).
}

utilized to pay for the more expensive patented and new innovative products that are needed to treat some diseases where generic medicines are not available. ${ }^{10}$ Hence, the wide use of generic medicines is instrumental to the creation and maintenance of sustainable healthcare systems. ${ }^{11}$ Therefore, healthcare professionals are encouraged to promote generic medicines to their patients.

\section{Generic substitution as a method to promote generic medicines}

To promote generic medicines, generic substitution (GS) and generic prescribing are adopted in many healthcare systems. ${ }^{12} \mathrm{GS}$ can be defined as an act of dispensing an equivalent generic medicine when a branded medicine is prescribed (i.e. switching the patient from an original brand medicine to an equivalent generic medicine), while generic prescribing is defined as prescribing by the approved Non-Proprietary Name (INN) of the medicines. ${ }^{13}$ However, GS is not a simple task that involves switching from an original brand to another, but rather a task that should be done after considering 
many factors related to the medicine itself, the patient, the physicians and the regulations, and should be based on several clinical and non-clinical considerations. The considerations include patient preference, patient consent, prescriber's approval (if needed), patient's understanding of the difference between the medicine brands to prevent any confusion due to brand changing (especially for some patients, e.g. the elderly), consistency in the selection of the brand especially for chronic and long-term therapy, the assessment of allergy history to any inactive ingredients, if the new brand needs different instructions to handle, and the patient's familiarity with the brand (e.g. metered dose dry powder inhalers, somatropin injection cartridges) ${ }^{14-18}$ In addition, patients need to be educated about generic medicines in terms of quality, safety, efficacy, bioequivalence and the similarities and differences between them and the original brands. Therefore, healthcare professionals need to assess the suitability of GS based on their professional judgment. ${ }^{19}$ However, more importantly, one of the essential steps in performing GS is that the generic medicine must be bioequivalent and therapeutically equivalent to the original brand medicine. Thus, unlike other factors that need to be considered when performing GS, therapeutic equivalence should be based on scientific evidence rather than professional judgment of individual healthcare professionals, as GS is not appropriate for some medicines. For example, Narrow Therapeutic Index (NTI) drugs such as anti-arrhythmic drugs (e.g. Digoxin, disopyramide), anticoagulant drugs (e.g. Warfarin), antiepileptic drugs (e.g. Carbamazepine, phenytoin, valproic acid), and anti-rejection drugs (e.g. Cyclosporine, sirolimus, tacrolimus). Other examples include modified release preparations of medicines (e.g. carbamazepine, theophylline, diltiazem, aminophylline, nifedipine, morphine and oxycodone), medicines containing more than one active ingredient (e.g. some topical preparations, oral contraceptives, antacids preparations containing simethicone), different products of the same active ingredient that have different licensed indications (e.g. sildenafil $\left(\right.$ Viagra $^{\circledR}$ or Revatio $\left.{ }^{\circledR}\right)$ ), and products using different salts to form the active ingredients (e.g. amitriptyline, nortriptyline). ${ }^{13,18,20,21}$

Therefore, many countries have produced evidence-based guides to ensure that GS is appropriate. One of the examples is the "Approved Drug Products with Therapeutic Equivalence Evaluations", commonly known as the Orange Book, ${ }^{19}$ which is a useful guide for pharmacists and other healthcare professionals as regards therapeutic equivalence and approved generic medicines in the US. In this list, products that are therapeutically equivalent where there is adequate evidence supporting bioequivalence are designated with a code " $A$ ", and products that are not therapeutically equivalent, where there is no adequate evidence supporting bioequivalence, are designated with a code "B". Another example is the Schedule of Pharmaceutical benefits in Australia, which is a useful guide for healthcare professionals and consumers as regards therapeutic equivalence between medicines. ${ }^{22}$ In the Australian schedule, "a" precedes the names of therapeutically equivalent and interchangeable medicine brands, whereas " $b$ " is attached to brands of the medicine that are equivalent to the original brand but there is no evidence of equivalency between them and other products marked with "a". For other medicines not marked with a or b, their therapeutic equivalence is not known; hence, caution should be exercised when GS is done. In Denmark, The Royal Dutch Pharmacists Association (KNMP) has produced a professional guideline for community pharmacists regarding GS. The guideline is aimed to help CPs to perform GS appropriately by providing principles and guidance when performing GS. The guideline addressed the issue of NTI drugs and other drugs for which GS is not appropriate. In addition, it addressed the prescription of biological and biosimilars. Furthermore, it addressed random substitution and the general considerations and factors that need to be taken into account, such as the factors related to patients, factors related to prescribers and legal issues. ${ }^{23,24}$

\section{Generic substitution in Saudi Arabia}

In Saudi Arabia, generic medicines are registered via an evidence-based rigorous scientific process to ensure the efficacy, safety and quality of medicines. ${ }^{25}$ Furthermore, Saudi Food and Drug Authority (SFDA), which is the drug regulatory body in Saudi Arabia, requires the demonstration of bioequivalence before registration and it can be waived only if scientifically appropriate. ${ }^{26}$ Registered medicines are listed in the Saudi National Formulary (SNF) and are also listed in the directory of registered medicines in Saudi Arabia, which can be accessed online via the SFDA website. ${ }^{27}$ The SNF contains full prescribing information about registered medicines, including trade names of products and their prices. However, there is no information in the SNF about bioequivalence evaluation and therapeutic interchangeability to guide GS and generic prescribing by healthcare professionals.

In Saudi Arabia, GS is permissive, as pharmacists are allowed to perform generic substitution according to article no. 23 of the Practice of Health Professions Act 2005. While prescriber's permission is not a requirement, patient consent is required. ${ }^{28}$ Pharmacists are not allowed to perform generic substitution for Narrow Therapeutic Index (NTI) Drugs according the Executive Regulations of Practice of Health Profession Act 2006. ${ }^{29}$ However, there is no list available to pharmacists and other healthcare professionals about NTI drugs and other medicines that are not suitable for GS.

To guide GS, there is evidence in the literature of the importance of having a formulary of interchangeable medicines to facilitate appropriate GS. ${ }^{30-33}$ For instance, Johnston et al (2011) recommended that evidence regarding therapeutic equivalence should be made available to the public and that best practice guidelines are required for GS. ${ }^{33}$ Furthermore, Hassali et al (2012) concluded that to promote responsible generic substitution, a formulary of interchangeable medicines must be developed to guide GS. The formulary should also contain the list of the products that are not suitable for GS; such a formulary would help both prescribers and pharmacists to assess the generic equivalence of the products offered as alternative substitutes. ${ }^{32}$

\section{Conclusion}

In conclusion, we believe that it is instrumental to have a formulary of interchangeable products to guide responsible GS or at least include such vital information in the SNF to make healthcare professionals more confident when providing GS and to avoid situations where GS is inappropriate.

\section{Conflicts of interest}

All authors have none to declare.

\section{References}

1. Godman B, Wettermark B, Bishop I, Burkhardt T, Fürst J, Garuoliene K. European payer initiatives to reduce prescribing costs through use of generics. GaBI J. 2012;1:22-27.

2. Ministry of Health. Labour and Welfare of Japan. Policy Report: Promotion of the Use of Generic Drugs; 2012. Available at: http://www.mhlw.go.jp/english/ policy_report/2012/09/120921.html. Accessed 20.04.13.

3. Andersson K, Bergstrom G, Petzold M, Carlsten A. Impact of a generic substitution reform on patients' and society's expenditure for pharmaceuticals. Health Policy. 2007;81:376-384.

4. Coombes R. GPs save $£ 400 \mathrm{~m}$ in 2008 by increasing use of generic drugs. BMJ. 2009;338:b2044. 
5. Generic Pharmaceutical Association. GPhA report: savings: $\$ 1$ trillion over 10 years - generic drug savings in the U.S. J Pharm Health Serv Res. 2012;3:229-236.

6. Sheppard A. Generic Medicines: Essential Contributors to the Long-Term Health of Society. IMS Health. Available at: http://www.imshealth.com/ imshealth/Global/Content/Document/Market_Measurement_TL/Generic_ Medicines_GA.pdf. Accessed 4.02.13.

7. European Generic Medicines Association (EGA). EGA fact sheet on generic medicines: the Overall Contribution of generic medicines to healthcare \& Enterprise. Available at: http://198.170.119.137/doc/ega_factsheet-01.pdf. Accessed 18.05.13.

8. Godman B, Shrank W, Wettermark B, et al. Use of generics-a critical cost containment measure for all healthcare professionals in Europe? Pharmaceuticals. 2010:3:2470-2494.

9. European Generic Medicines Association (EGA). Ega Fact Sheet on Generic Medicines: Generic Medicines Provide Front-Line Treatment for Chronic Illnesses \& Conditions. Available at: http://198.170.119.137/doc/ega_factsheet02.pdf. Accessed 18.05.13.

10. European Generic Medicines Association (EGA). Frequently Asked Questions About Generic Medicines; 2007. Available at: http://198.170.119.137/doc/FAO generics.pdf. Accessed 18.05.13.

11. Simoens S. Creating sustainable European health-care systems through the increased use of generic medicines: a policy analysis. J Generic Med: Business J Generic Med Sec. 2010;7:131-137.

12. Vogler $S$. The impact of pharmaceutical pricing and reimbursement policies on generics uptake: implementation of policy options on generics in 29 European countries-an overview. GaBI J. 2012;1:93-100.

13. Ferner RE, Lenney W, Marriott JF. Controversy over generic substitution. BMJ 2010;340:c3570.

14. Hassali MAA, Thambyappa J, Shafie AA. What you Should Know About Generic Medicines. Penang, Malaysia: Penerbit Universiti Sains Malaysia; 2012.

15. International Society of Drug Bulletins (ISDB). ISDB Newsletter; 2006. 20(3 (special issue on INN)).

16. National Prescribing Service Limited (NPS). Generic Medicines: Same Difference?; 2006. Available at: http://www.nps.org.au/_data/assets/pdf_file/0020/ 15842/news44_generic_medicines_0206.pdf. Accessed 9.05.13.

17. National Prescribing Service Limited (NPS). Generic Medicines: Dealing with Multiple Brands; 2007. Available at: http://www.nps.org.au/_data/assets/pdf_ file/0008/23867/news55_generic_medicines_1207.pdf. Accessed 9.05.13.

18. Duerden MG, Hughes DA. Generic and therapeutic substitutions in the UK: are they a good thing? Br J Clin Pharmacol. 2010;70:335-341.

19. U.S. Department of Health and Human Services-FDA/CDER. Office of Generic Drugs Orange Book: Approved Drug Prod Ther Equivalence Evaluations; 2012. Available at:
32: http://www.fda.gov/downloads/Drugs/DevelopmentApprovalProcess/UCM07 1436.pdf. Accessed 10.01.13.

20. Lewek P, Kardas P. Generic drugs: the benefits and risks of making the switch. J Fam Pract. 2010;59:634-640.

21. Holmes DR, Becker JA, Limacher MC, Page RL, Sila C. ACCF/AHA 2011 health policy statement on therapeutic interchange and substitution: a report of the American College of Cardiology Foundation Clinical Quality Committee. Circulation. 2011;124:1290-1310.

22. Department of Health and Aging. Australian Government. Schedule of Pharmaceutical Benefits; 2013. Available at: http://www.pbs.gov.au/publication/ schedule/2013/01/2013-01-01-pbs-schedule.pdf. Accessed 20.01.13.

23. Grandia L, Vulto A. Generics substitution in primary care: summary of the Dutch community pharmacies guidelines. GaBI J. 2012;1:102-103.

24. Royal Dutch Pharmacists Association (KNMP). Guideline for Generic Substitution; 2012. Available at: http://www.knmp.nl/downloads/producten-diensten/ farmacotherapie/handleiding.geneesmiddelsubstitutie.engels.201202.pdf/ view. Accessed 16.05.13.

25. Saudi Food \& Drug Authority (SFDA), Kingdom of Saudi Arabia. Data Requirements for Human Drugs Submission: Content of the Dossier (Version 1.1); 2011. Available at: http://www.sfda.gov.sa/en/drug/drug_reg/Regulations/Data \%20Requirements\%20for\%20Human\%20Drugs\%20Submission\%20version\%201. 1.pdf. Accessed 18.05.13.

26. Executive Board of the Health Ministers' Council for GCC States. The GCC Guidelines for Bioequivalence (version 2.1); 2011. Available at: http://www.sfda. gov.sa/en/drug/drug_reg/Regulations/GCC\%20\%20Guidelines\%20for\% 20Bioequivalence_Final\%203-2013.pdf. Accessed 18.05.13.

27. Saudi Food \& Drug Authority (SFDA), Kingdom of Saudi Arabia. Registered Drug List; 2013. Available at: http://www.sfda.gov.sa/en/drug/Pages/default.aspx. Accessed 18.05.13.

28. Practice of Health Professions Act Riyadh, Saudi Arabia; 2005.

29. Executive Rules of Practice of Health Professions Act Riyadh, Saudi Arabia; 2006.

30. Chong CP, Hassali MA, Bahari MB, Shafie AA. Evaluating community pharmacists' perceptions of future generic substitution policy implementation: a national survey from Malaysia. Health Policy. 2010;94:68-75.

31. Chua GN, Hassali MA, Shafie AA, Awaisu A. A survey exploring knowledge and perceptions of general practitioners towards the use of generic medicines in the northern state of Malaysia. Health Policy. 2010;95:229-235.

32. Hassali MA, Thambyappa J, Saleem F. Generic substitution in Malaysia: recommendations from a Systematic Review. J App Pharm Sc. 2012;2:159-164.

33. Johnston A, Asmar R, Dahlöf B, et al. Generic and therapeutic substitution: a viewpoint on achieving best practice in Europe. Br J Clin Pharmacol. 2011;72: 727-730. 